\title{
Retrato de infancia en Mário de Andrade: fotografía, memoria y viaje
}

\author{
Alejandra Josiowicz \\ COC/Fiocruz
}

\begin{abstract}
Resumo
O trabalho investiga o retrato de infância em textos literários e fotografias de Mário de Andrade a partir de duas modalidades distintas: por um lado, o retrato de infância como instrumento de autofiguração, tal como aparece na ficção autobiográfica, "Tempo da camisolinha" (1939-1943), e nas reflexões de Walter Benjamin e Roland Barthes, isso é, como revelação de um sujeito moderno deslocado e de uma cisão entre o eu e sua representação. Por outro lado, analiso as fotografias de crianças que Mário de Andrade produziu durante sua viagem à Amazônia e ao Nordeste brasileiro como modalidades da investigação estética e sociocultural, que apresentam um encontro conflitivo e tensionado entre o fotógrafo e os sujeitos retratados, no qual o primeiro se expõe e se visibiliza no ato da representação, e os segundos interpelam e transformam o espaço fotográfico.
\end{abstract}

Palavras chave: Infância; fotografia; memória; viagem.

\section{Resumen}

El trabajo investiga el retrato de infancia en textos literarios y fotografías de Mário de Andrade a partir de dos modalidades distintas: por un lado, el retrato de infancia como instrumento de auto-figuración, tal como aparece en la ficción autobiográfica, "Tempo da camisolinha” (1939-1943), y en las reflexiones de Walter Benjamin y Roland Barthes, es decir, como revelación de un sujeto moderno dislocado y de una cesura entre el yo y su representación. Por otro lado, analizo las fotografías de niños que Mário de Andrade sacó durante sus viajes al Amazonas y al Nordeste brasileño como modos de investigación estética y sociocultural, que ponen en escena un encuentro conflictivo y tensionado entre el fotógrafo viajante y los sujetos retratados, por el cual el primero se expone y visibiliza en el acto de la representación y estos últimos interpelan y transforman el espacio fotográfico.

Palabras clave: infancia; fotografía; memoria; viaje. 
1. Sobre el tema, consultar FABRIS, Annateresa. Identidades Virtuais: uma leitura do retrato fotográfico, 2004.
2. Ver, al respecto, BERGER, John. "The Changing View of Man in the Portrait", 2003.
Este trabajo busca reflexionar sobre la fotografía de infancia en Mário de Andrade a través de dos modalidades diferentes: por un lado, como instrumento de rememoración y autofiguración - el retrato de infancia como modo de exploración del yo $-\mathrm{y}$, por otro, como una forma de investigación social - de la alteridad, la diversidad y la desigualdad socio-culturales. En el caso de la primera modalidad, analizaré la presencia de la fotografía de infancia en la ficción autobiográfica "Tempo da camisolinha" (1939-1943), en relación con las reflexiones que Walter Benjamin y Roland Barthes realizaron sobre ella como puesta en escena de un sujeto moderno dislocado. En el caso de la segunda, examino las fotografías de niños que Mário de Andrade sacó durante sus viajes al Amazonas y al Nordeste brasileño, y las anotaciones o glosarios que las acompañan, a la vez registro de viaje y ensayo de experimentación estética, en las que leo una fuerte interpenetración entre el escritor-fotógrafo y el "otro" fotografiado. Con este fin, el ensayo se focaliza en el retrato fotográfico de infancia, tal como es movilizado por la narración autobiográfica y el registro de viaje y, sobre todo, como modalidad estética de experimentación.

\section{I.}

El retrato fotográfico, heredero de la tradición pictórica, funcionó, a partir del Siglo XIX en Europa y los Estados Unidos, como una suerte de instantánea psicológica, coherente con las nuevas necesidades de auto-representación propias de las clases medias en ascenso ${ }^{1}$. En tanto tal, el retrato - a través de sus diversas modalidades, entre las cuales sobresalen las cartes de visite - creó una serie de estereotipos sociales, una galería de personajes y papeles con sus correspondientes poses, vestidos, accesorios y escenarios, como signos visuales que teatralizan su integración social. Los fondos, el encuadre, los trajes y accesorios, la representación de cuerpo entero, la distancia focal entre el fotógrafo y el modelo, el direccionamiento de la luz y el contraste entre claros y oscuros apuntaban a una retórica de la inteligibilidad y a transformar en imagen la deseada estabilidad y legitimidad de las clases medias en ascenso. Así, el individuo que se coloca en pose se inscribe en un sistema simbólico que confirma su posición social: el retrato, acto social y de sociabilidad, funciona como herramienta de auto-confirmación y conciencia de sí, a través de la presencia indispensable de la mirada de otro. Sin embargo, a la vez que contribuye a la popularización del uso público y privado del retrato, la fotografía pone en escena una crisis en la representación, conectada con una crisis más amplia de la subjetividad moderna, incontenible en una serie de trazos fijos e incompatible con un estereotipo social estable $^{2}$. Al mismo tiempo que funciona como instrumento de 
confirmación del ser social y su identidad, la fotografía permite descomponerlo, desestabilizarlo, mostrar lo que no es: como un espejo falsamente mimético. ${ }^{3}$

Como parte de la transformación en las actitudes sociales y culturales respecto de la infancia - que se inicia en el Siglo XVIII en el caso de Europa, según ha estudiado Philippe Ariès -, el arte pictórico desarrolló una nueva serie de convenciones para representar a los niños, inicialmente ligadas a la representación sacra del niño Jesús y de los ángeles y que luego se trasladarían al ámbito secular ${ }^{4}$. Como parte del proceso de privatización de la vida familiar, el retrato infantil - imbuido de una intensa carga afectiva, sentimental - se volvería, a partir de entonces, un núcleo organizador de la representación familiar. Ya a partir de fines del Siglo XIX, la fotografía posibilitó la entrada y la circulación de imágenes infantiles y familiares - a través de cartes de visite, ilustraciones en revistas, calendarios, etc. - en el ámbito del hogar. Este tipo de retratos infantiles tendió a seguir una serie de modelos más o menos fijos - niños ángeles o querubines, niños disfrazados, niños con mascotas o como adultos en miniatura -, en que la infancia aparecía asociada a ideas de inocencia, pureza y atemporalidad, aparentemente libre de marcas histórico-sociales y, en tanto tal, vehículo paradigmático de fantasías nostálgicas adultas $^{5}$. En este sentido, como puesta en escena del carácter aparentemente evanescente del niño representado, la fotografía infantil, en su vertiente comercial, mostraría una tendencia a esconder la espesura del propio instrumento fotográfico.

Sin embargo, en su reflexión sobre el retrato fotográfico de infancia, Walter Benjamin ya señalaba su carácter de simulacro y teatralización de la identidad social. Benjamin comenta una foto de sí mismo cuando niño, posando, vestido y rodeado de accesorios en un estudio fotográfico: cantando como un tirolés, agitando un sombrero sobre un fondo de picos nevados, o como un marinero, de pie, recostado contra un pilar. ${ }^{6}$ Estos atelieres, "con sus cortinados y palmeras, tapices y caballetes" eran, a la vez, dice Benjamin, "cámara de tortura y trono", ejecución, castigo y modo honorífico de la representación. El retrato del niño - altamente formalizado a través del fondo, la pose, la vestimenta, los accesorios y escenarios - constituye un modo de exhibición de la legitimidad familiar. El niño, agobiado por un aparato ornamental excesivo, aparece aquí como parte de una retórica de la imagen destinada a confirmar la estabilidad y la prosperidad de la familia ante la mirada de los otros. Benjamin lee estos retratos de niños en atelieres ya no como imágenes de inocencia, sino en tanto reveladores de una crisis en la subjetividad moderna, incontenible en su representación social. Así, afirma sobre una fotografía infantil de Kafka:
3. BRIZUELA, Natalia. Depois da fotografia: uma literatura fora de si, 2014.

4. ARIÈS, Philippe, Centuries of Childhood: a Social History of Family Life, 1962.

5. Para un análisis de las representaciones visuales de la infancia, ver el estudio pionero de Anne HIGONNET, Anne Pictures of Innocence: The History and Crisis of Ideal Childhood, 1998.

6. BENJAMIN, Walter. "Little History of Photography", 1999. p. 515. 
A boy of about six, dressed in a tight-fitting, almost deliberately humiliating child's suit, overladen with lace, is seen standing in a kind of wintergarden landscape. The background teems with palm fronds. And as if to make these upholstered tropics still stickier and sultrier, the subject holds in his left hand an immoderately large hat with a broad brim of the type worn by Spaniards. He would surely disappear into the setting, were it not for his immeasurably sad eyes, which dominate the landscape that has been predestined for them. This picture in its infinite sadness forms a pendant to the early photography where the people did not, as yet, look out at the world in so excluded and godforsaken a manner as this boy. ${ }^{7}$

El niño Kafka, de unos seis años, aparece vestido con un traje ajustado, recargado de puntillas, sosteniendo un sombrero demasiado grande, de ala ancha, humillado y sofocado por el paisaje tropical. Su mirada inmensamente triste, desolada, pone en escena la no coincidencia del sujeto consigo mismo, su desestabilización, aquello que la fotografía de atelier, con sus fondos, trajes y accesorios excesivos, buscaba incesantemente ocultar. Esa fotografía infantil funciona - en lugar de como auto-confirmación o como dadora de legitimidad -, como puesta en escena del subconsciente, señalando la dislocación fundamental entre el sujeto y su representación, la cesura entre el yo y su escenificación que sería propia, según Benjamin, de la fotografía moderna.

En Infancia en Berlin en 1900, por otro lado, Benjamin vuelve sobre su propio retrato de infancia y afirma:

...why I was at such a loss when someone demanded of me similarity to myself. This would happen at the photographer's studio. Wherever I looked, I saw myself surrounded by folding screens, cushions, and pedestals, which craved my image much as the shades of Hades craved the blood of the sacrificial animal. In the end, I was offered up to a crudely painted prospect of the Alps, and my right hand, which had to brandish a kidskin hat, cast its shadow on the clouds and snowfields of the backdrop. But the tortured smile on the lips of the little mountaineer is not as disturbing as the look I take in now from the child's face, which lies in the shadow of a potted palm. (...). I am standing there bareheaded, my left hand holding a giant sombrero, which I dangle with studied grace. My right hand is occupied with a walking stick, whose curved handle can be seen in the foreground while its tip remains hidden in a cluster of ostrich feathers spilling from a garden table. Over to the side, near the curtained doorway, my mother stands motionless in her tight bodice. As through attending to a tailor's dummy, she scrutinizes my velvet suit, which for its part is laden with braid and other trimming and looks like something out of a fashion magazine. I, however, am distorted by similarity to all that surrounds me here. ${ }^{8}$ 
El niño aparece en el atelier fotográfico, vestido con un traje de terciopelo recargado con todo tipo de ornamentos, sosteniendo un sombrero de ala ancha con gesto estudiado y, en la otra mano, un bastón, y rodeado de accesorios escenográficos, almohadones, pedestales y palmeras artificiales sobre un fondo alpino. El abarrotado estudio fotográfico, el fondo, la pose, los trajes y accesorios, al intentar constituirse en signos de legitimidad y herramientas de auto-confirmación, avanzan sobre la sonrisa torturada del niño, como si quisieran devorarlo. De este modo, el rostro perturbador del niño y su postura artificiosa, como un maniquí, funciona como espejo deformado de la fantasía familiar: el retrato infantil, convencionalmente ligado a la carga sentimental de la vida doméstica, aparece como su doble fantasmal, revelando la no coincidencia del sujeto consigo mismo, como un reflejo simulado e imposible del yo.

Por su lado, en Roland Barthes por Roland Barthes (1975), Roland Barthes también ha reflexionado sobre el retrato fotográfico de infancia. Escribe, junto a una fotografía de un niño en la playa, con un sombrero en pico y de ala ancha, absorto en su juego:

De mi pasado, es la infancia lo que más me fascina: sólo ella, al mirarla, no me hace lamentar el tiempo abolido. Pues no es lo irreversible lo que en ella descubro, sino lo irreductible: todo lo que está todavía en mí, por acceso; en el niño, leo a cuerpo descubierto el reverso negro de mí mismo, el tedio, la vulnerabilidad, la aptitud para las desesperaciones (afortunadamente plurales), la conmoción interna, cercenada desgraciadamente de toda expresión.?

Barthes detecta una extrañeza irreducible en la fotografía de infancia. En lugar de como marca, en clave nostálgica, de un referente perdido, es signo de lo irreconocible, lo inidentificable en el sujeto: una sombra pulsional de sí mismo, muda y que no deja más huella que su propia persistencia inescapable. Al mirar la fotografía infantil no es el pasado lo que emerge sino una sombra de sí mismo, una fuerza pulsional que persiste, obstinada. En la fotografía que aparece junto al texto, de hecho, el rostro del niño está casi borroneado, invisible a la cámara, carente de marcas que confirmen su identidad.

Asimismo, en "Tempo da camisolinha" (1939-1943), de Mário de Andrade - que ha sido considerado por la crítica como una ficción autobiográfica ${ }^{10},-$ el narrador describe un retrato fotográfico de infancia:

Me lembro de uma fotografia minha desse tempo, que depois destruí por uma espécie de polidez envergonhada... Era já agora bem homem e aqueles cabelos adorados da infância me pareceram de repente como um engano
9. BARTHES, Roland. Roland Barthes por Roland Barthes, 2004, p. 38.

10. Ver el comentario de Telê Ancona Lopez, en "Um contista bem contado", 1996, p. 91. 
11. Andrade, Mário de. Contos novos. Rio de Janeiro: Nova Fronteira, 2011, p. 135.
12. Ibidem. p. 135-136. grave, destruí com rapidez o retrato. Os traços não eram felizes mas na moldura da cabeleira havia sempre um olhar manso, um rosto sem marcas, franco, promessa de alma sem maldade. ${ }^{11}$

En este primer retrato, el niño aparece asociado, no a la belleza, sino a una suerte de mansedumbre, a una sinceridad sin dobleces, una falta de límites y una desnudez ligada a los cabellos nunca cortados. La fotografía señala un exceso, un "engaño grave" en los cabellos largos, de los que el adulto, "bien hombre", se avergüenza. Como puesta en escena de una pulsión incivilizada, ligada al ridículo, el adulto decide destruir ese retrato de infancia. En cambio, guarda otro, en que posa, ya con los cabellos cortados, vestido con una camisita de terciopelo y junto al hermano mayor:

De um ano depois do corte dos cabelos ou pouco mais, guardo outro retrato tirado junto com Totó, meu mano. Ele, quatro anos mais velho que eu, bem garboso e completamente infantil numa bonita roupa marinheira; eu, bem menor, ainda conservo uma camisolinha de veludo, muito besta, que minha mãe por economia teimava utilizar até o fim.

Guardo esta fotografia porque se ela não me perdoa do que tenho sido, ao menos me explica. Dou a impressão de uma monstruosidade insubordinada. Meu irmão, com seus oito anos, é uma criança integral, olhar vazio de experiência, rosto rechonchudo e lisinho, sem caráter fixo, sem malícia, a própria imagem da infância. Eu, tão menor, tenho esse quê repulsivo do anão, pareço velho. E o que é mais triste, com uns sulcos vividos descendo das abas voluptuosas do nariz e da boca larga, entreaberta num risinho pérfido. Meus olhos não olham, espreitam. Fornecem às claras, com uma facilidade teatral, todos os indícios de uma segunda intenção. ${ }^{12}$

En este retrato, el hermano mayor, vestido de marinero, símbolo de elegancia infantil, contrasta con el narrador que, con su camisita - que da título al relato - señala un exceso o una falta en la naturaleza misma de la infancia. Mientras el hermano es un niño inocente, imagen de la pureza, de rostro angelical y sin marcas, el narrador escenifica la infancia como perturbación, "monstruosidad insubordinada". Si bien es menor, parece viejo, un "enano" "repulsivo", figura de una corrupción precoz. Las arrugas que surcan el rostro infantil, la risa pérfida y la mirada desconfiada revelan, "con una facilidad teatral", una duplicidad - una "segunda intención" -, una dislocación fundamental que constituye al sujeto en sí mismo y en su relación con el mundo. Este niño escenifica la ruina en el seno mismo de la infancia: es un caído, signo del doblez entre subjetividad y representación. Dice el narrador: 
Não sei por que não destruí em tempo também essa fotografia, agora é tarde. Muitas vezes passei minutos compridos me contemplando, me buscando dentro dela. E me achando. Comparava-a com meus atos e tudo eram confirmações. Tenho certeza que essa fotografia me fez imenso mal, porque me deu muita preguiça de reagir. Me proclamava demasiadamente em mim e afogou meus possíveis anseios de perfeição. ${ }^{13}$

Si el retrato fotográfico aparece aquí como herramienta de auto-exploración no es en el sentido de una retórica de la inteligibilidad sino, por el contrario, como puesta en escena de la alteridad del yo. La fotografía de infancia no se constituye aquí como objeto de nostalgia adulta sino que reenvía una y otra vez a una grieta en la subjetividad, erigiéndose, de este modo, en obstáculo de toda agencia individual, perversión de cualquier "posible anhelo de perfección". En este sentido, el retrato revela el carácter ya-representado de la propia infancia, como puesta en escena de un yo desdoblado, corrupto desde el vamos, incapaz de "reacción”.

\section{II.}

Durante los dos viajes más extensos que realiza por Brasil - el primero, al Norte (por los estados de Amazonas y Pará, hasta Perú y la frontera con Bolivia) durante 1927 y el segundo, al Nordeste (Alagoas, Rio Grande do Norte, Paraíba e Pernambuco) en 1928 y 1929, Mário de Andrade sacó una serie de fotografías, que fueron reveladas posteriormente en blanco y negro ${ }^{14}$. Andrade fue un fotógrafo autodidacta, cuyo interés teórico en la fotografía como lenguaje se evidencia en las revistas y libros presentes en su biblioteca, así como en varios de sus ensayos ${ }^{15}$. Como una suerte de diario de viaje y también como correlato de su interés por el registro documental y etnográfico, Andrade saca fotos ("fota”) con su máquina Kodak modelo de fuelle (rebautizada como "codaque") y experimenta con la composición fotográfica y visual como lenguaje estético, explorando encuadramientos e iluminaciones. En paralelo, escribe al dorso de las fotografías una serie de títulos y subtítulos, como un desdoblamiento más del diario de viaje, en los que, además de las informaciones fácticas (el lugar, la fecha) y de orden técnico (como apertura del diafragma, posición del sol), incluye una serie de glosas poéticas ${ }^{16}$. Si bien no es posible asimilar el carácter y propósito del primer y segundo viaje de Andrade, analizaremos fotografías de infancia provenientes de ambos, considerando que conjugan - aunque no sin diferencias -, un interés por la cultura y el espacio social amazónico y nordestino con la experimentación estética a partir del lenguaje fotográfico ${ }^{17}$. Las numerosas fotografías de niños que toma durante sus viajes traspasan el registro personal o documental,
13. Ibidem, p. 136

14. Las fotos son parte del archivo del escritor, conservadas en el Arquivo Mário de Andrade, Instituto de Estudos Brasileiros de la Universidade de São Paulo, Série Fotografias.

15. Sobre el tema, ver LopeZ, Telê Ancona. "O turista aprendiz na Amazônia: a invenção no texto e na imagem" Anais do Museu Paulista. V. 13. N. 2. 2005, y LopeZ, Telê Ancona et Raniero Fernandez, Leandro, "Os diários do fotógrafo", 2015. Ancona Lopez considera a las fotografías un "diário imagético”, es decir, un diario de viaje en imágenes.

16. Afirman Ancona Lopez y Rainero Fernandez al respecto: "[...] vale admitir o diário das legendas como o conjunto textual dos fragmentos que retém ou modifica a versão da matéria escrita no passado e se vê acrescido, em muitos casos, da re-viagem no olhar do poeta que contempla as fotos e, com a mão mais leve no lápis, exerce o lirismo e o humor, cita ou parodia autores, improvisa quadrinhas ou embarca na avaliação." Ibidem, p. 452.

17. André Botelho ha señalado la necesidad de diferenciar entre ambos viajes y no asimilar unívocamente el carácter etnográfico del segundo al primero "como se uma mesma ideia de etnografia e uma mesma ideia de viagem estivessem em jogo num e noutro caso, como também [a necessidade de não] reificar sua confluência para a afirmação de um mesmo regime de autoridade etnográfica." BOTELHO, André. "A viagem de Mário de Andrade à Amazônia: entre raízes e rotas." Revista do Instituto de Estudos Brasileiros, 2013. Sobre el segundo viaje, ver CAMPOS, Luna Ribeiro. "Sensibilidade etnográfica, narrativa e interpretação do Brasil: a viagem de Mário de Andrade ao Nordeste (1928-1929), 2014. 
18. He estudiado el tema en mi tesis de doctorado, La cruzada de los niños. Infancia y cultura en América Latina (1880-1980), 2013, y en el artículo "Por uma política da estética em Mário de Andrade: Expressionismo e Infância”, 2015.

\section{Las cantigas y canciones} de cuna recopiladas por Mário de Andrade se encuentran en el Arquivo Mário de Andrade, Instituto de Estudos Brasileiros de la Universidade de São Paulo.

20. Sobre el tema, ver COUTINHO, Rejane Galvão "A coleção de Desenhos Infantis do Acervo Mário de Andrade", 2002.

21. También constan en el Arquivo Mário de Andrade, Instituto de Estudos Brasileiros de la Universidade de São Paulo, los apuntes de sus clases sobre el desarrollo estético infantil. Publicado en MOTTA, Flávio (Org.). Depoimentos 2/ Mário de Andrade, 1966.

22. André Botelho ha analizado el relato de viaje al Amazonas de Mário de Andrade como modo de redescubrimiento de Brasil y encuentro del escritor con la diversidad cultural y la desigualdad social, a partir del concepto de empatía. Afirma Botelho: "Empatia é a categoriachave para compreender a perspectiva não apenas do viajante, mas do intelectual e homem Mário de Andrade. Empatia forjada em um jogo complexo de estranhamentos e reconhecimentos, e não apenas de identificações. Empatia manifesta, sobretudo, com os homens e mulheres do povo e suas formas de sociabilidade, crenças e expressões artísticas populares que podem ajudar a problematizar certas leituras mais apressadas das suas relações intelectuais e sentimentais com o universo por lo que propongo leerlas en relación con su investigación estética y socio-cultural de la infancia, como modo de reflexión socio-cultural y sobre la propia representación. ${ }^{18}$

Como parte de su investigación etnográfica más amplia, Mário de Andrade se interesó en la cultura oral infantil: recopiló, recibió de otros y cotejó con sus propias memorias canciones de cuna y cantigas provenientes del Norte, Minas Gerais, São Paulo y Rio Grande do Norte, así como otras de origen portugués ${ }^{19}$. Además, con dibujos recopilados por él o entregados por amigos y colaboradores, Andrade organizó una verdadera colección de arte infantil con más de 2000 dibujos provenientes de diferentes regiones de $\mathrm{Brasil}^{20}$. Asimismo, durante su actuación como Director del Departamento de Cultura y Recreación del Municipio de São Paulo entre 1935 y 1938, Andrade desplegó una serie de políticas públicas destinadas al desarrollo artístico infantil y a la investigación social y etnográfica de niños paulistas provenientes de diversas clases sociales. Y, más tarde, en sus clases de Filosofía e Historia del Arte en la recién creada Universidade do Distrito Federal (UDF) en Rio de Janeiro, iniciaría un estudio etnográfico y psicológico de las expresiones estéticas infantiles, en el marco del cual teorizó sobre la capacidad plástica del niño a través de una teoría de inspiración antropológica del arte. ${ }^{21}$

Las fotografías que Mário de Andrade tomó durante sus viajes presentan el encuentro del escritor con la alteridad, la diversidad cultural y la desigualdad social, por lo que - tal como el relato de su viaje al Amazonas - pueden ser leídas como modos de producción, y no como meros registros, de sentidos tanto estéticos como sociales, así como reflexiones sobre la representación. ${ }^{22}$ Las fotografías ponen en escena el contacto del escritor/fotógrafo con una serie de formas de sociabilidad y expresiones culturales diferentes: lejos de reducir lo percibido en términos de una identidad paradigmática, exponen la incomodidad del intelectual - fotógrafo y la imposibilidad de pensar de un modo unidireccional el acto de la representación. ${ }^{23}$

Mário de Andrade se interesó por el arte primitivo y su relación con pulsiones estéticas primarias ${ }^{24}$ : sin embargo, las fotografías de sus viajes al Amazonas y al Nordeste se apartan de la "fantasía primitivista" - término con el que Hal Foster se ha referido a la idea, propia del surrealismo y otros movimientos de vanguardia, de que el "otro" cultural o social tendría acceso a una capacidad estética radicalmente liberadora, que sería ajena al sujeto burgués y constitutivamente subversiva de las convenciones sociales y los cánones estéticos. ${ }^{25}$ En lugar de como puesta en escena de una retórica paternalista en que el "otro" aparece idealizado o exotizado - pensado como portador de una supuesta potencia primordial de transgresión - estos retratos fotográficos son indicios de un encuentro, cargado 
de violencia, entre el fotógrafo, el sujeto fotografiado y la herramienta de representación. Más que como resultado de un distanciamiento entre el sujeto de la representación y el sujeto fotografiado o una estetización de este último, las fotografías reflexionan justamente sobre ese encuentro revelando el extrañamiento y la incomodidad que lo caracteriza. Es en este sentido que las fotografías de infancia de Mário de Andrade constituyen enunciados estético-políticos sobre la ciudadanía, ${ }^{26}$ como superficies de encuentro e interacción - cargadas de extrañamiento y complejidad - entre el fotógrafo y los fotografiados, en que lejos de buscar una mirada aparentemente objetiva, el sujeto de la enunciación toma una perspectiva autoanalítica, exponiéndose a sí mismo, volviéndose visible - y, por lo tanto, vulnerable - ante el otro de la fotografía.

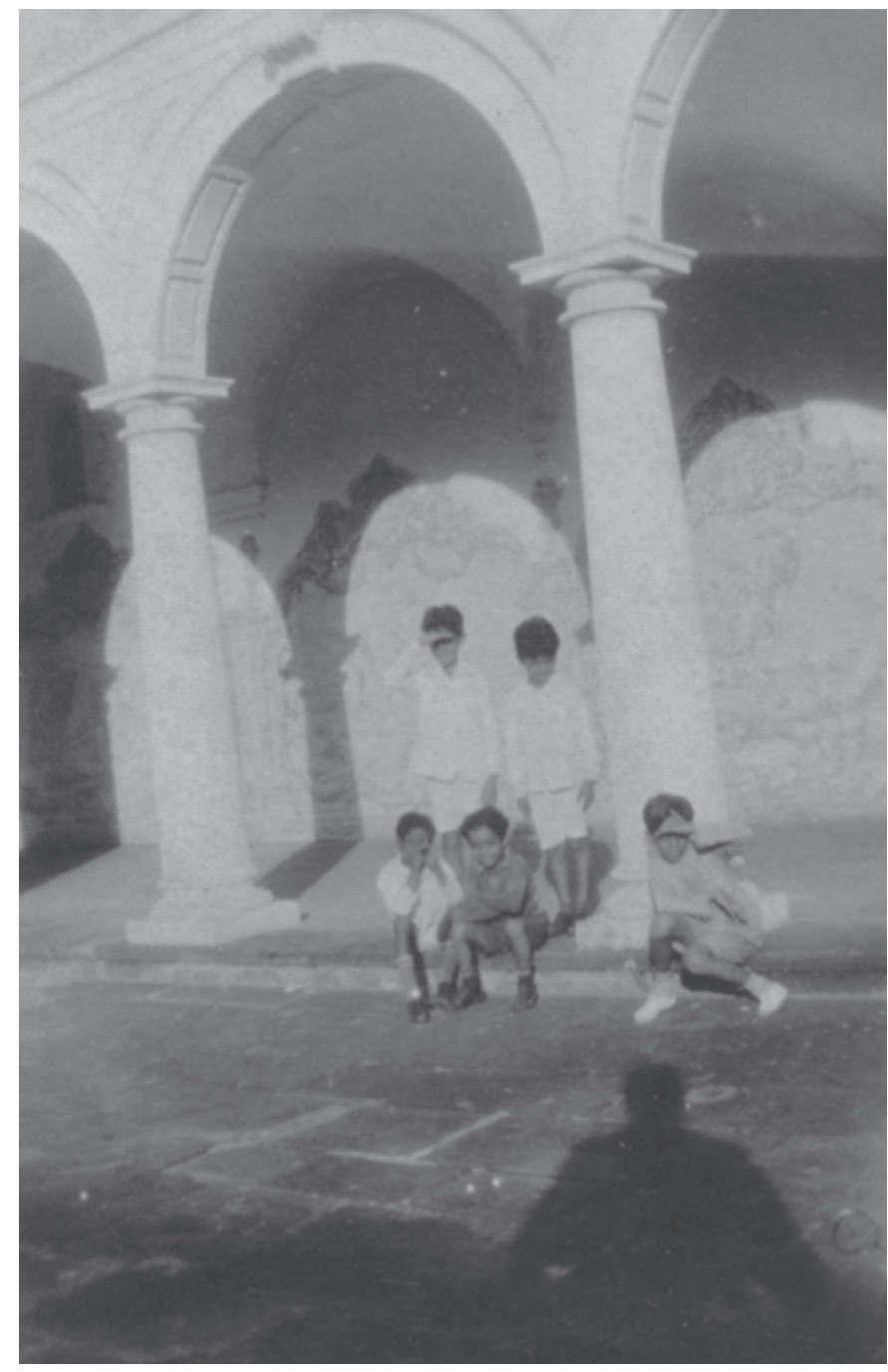

Fig. 1. "Claustro de São Francisco. Bahia”. Código MA- 0146 - IEB - USP

En la fotografía "Claustro de São Francisco. Bahía", aparece un grupo de niños, enmarcados en la arquitectura del popular". BOTELHO, André.

"A viagem de Mário de Andrade à Amazônia: entre raízes e rotas", Revista do Instituto de Estudos Brasileiros, 2013, p.

759. Ver también LIMA, Nísia

Trindade; BOTELHO, André.

"Malária como doença e perspectiva cultural nas viagens de Carlos Chagas e Mário de Andrade à Amazônia”, História, Ciências, Saúde - Manguinhos, 2013.

23. Para un análisis de las fotografías de Andrade como pioneras, en Brasil, de la investigación formal y la experimentación con el lenguaje fotográfico, ver CANJANI, Douglas. "Mário de Andrade fotógrafo-viajante e a linguagem modernista". Revista do Instituto de Estudos Brasileiros, 2013. Dice Canjani: "apesar de "amador", seu olhar (assim como sua relação técnica com a câmera) exibe maestria e vigor na apreensão de geometrias ínsitas ao campo visual, na exploração de luzes e contraluzes, na apropriação simbólica de elementos visuais de caráter narrativo." Ibidem, p. 55.

24. Son relevantes, en este sentido, las clases de su curso de Filosofía e Historia del Arte que impartió en la recién creada Universidade do Distrito Federal (UDF), en Rio de Janeiro. Publicadas en MOTTA, Flávio (Org.). Depoimentos 2/ Mário de Andrade, 1966.

25. FOSTER, Hal, "The Artist as Ethnographer?”, 1996.

26. Ariella Azoulay, en The Civil Contract of Photography, 2008, argumenta que la fotografía constituiría un espacio cívicopolítico, como documento que traspasa toda voluntad individual - dado que ninguno de los participantes puede determinar completamente el resultado - 
y es irreductible a una única narrativa. Para Azoullay, la fotografía es un espacio de definición y redefinición de la ciudadanía política, en que se debate el estatuto de lo fotografiado y en que el propio sujeto fotógrafo se expone, volviéndose visible.

27. ANDRADE, Mário de. $O$ Turista Aprendiz, 2015, p. 61. convento, vestidos presumiblemente con ropas escolares, que se encuentran mirando o, más bien, intentando dirigir sus miradas a la cámara. La foto traspasa el carácter de documentación arquitectónica - señalado por el título - para establecer un diálogo entre la arquitectura y un registro más subjetivo. Como el sol pega directamente sobre los rostros de los niños, estos se ven obligados a evitar la luz, ya sea tapándose los ojos con las manos, bajándolos o construyendo un visor con los dedos para espiar. De este modo, la fotografía incorpora un error o desvío aparente - el exceso de luz solar - al propio lenguaje fotográfico y lo constituye en instancia de la significación: la imagen se vuelve una especie de registro de la presencia del fotógrafo (cuya sombra aparece proyectada en el suelo) y de la voluntad fotográfica, sobre el objeto retratado. Por su lado, el fondo arquitectónico, que aparece sólo de modo parcial, enfatiza el sentido incompleto y la imposibilidad de conseguir un registro totalizante de lo visto. Así, la foto pone en escena el encuentro fallido del fotógrafo con los niños fotografiados, donde la voluntad de ver y volver visible, propia del viajante, nubla la propia representación. La gestualidad de los niños funciona de modo especular, como un reflejo o una puesta en escena de la voluntad de retratar, y de la imposibilidad o la dificultad de ver, si considerada en términos de una inteligibilidad absoluta. El mismo día en que toma esta foto, 13 de mayo de 1927 en San Salvador de Bahía, Mário de Andrade escribe en su diario de viaje:

E desde a noite da partida que estou querendo não apresentar alguém. É uma americaninha, girl etê, com muito açúcar e fotogénica duma vez. Faz de conta que não sei absolutamente nada de inglês, tiro fotografias. Foi um encanto conversarmos só de olhos e gestos. Nunca olhei tão olhado em minha vida e está sublime. Talvez por causa disso ela me amou eternamente, mas foi obrigada a ficar na Bahia porque não posso ter complicações. ${ }^{27}$

Esta niña norteamericana, fotografiable y fotografiada, como los niños de "Claustro de São Francisco", abre la posibilidad de un encuentro fotográfico en base a miradas y gestos. También aquí, el sujeto retratado devuelve la mirada y el fotógrafo se torna sujeto observado. Más que una inteligibilidad plena o una intención documental, el pasaje citado pone en escena el contacto entre lenguajes y horizontes culturales distintos - el del intelectual citadino y la joven norteamericana, ambos ajenos a San Salvador - como un juego de máscaras marcado por el extrañamiento y la simulación. 


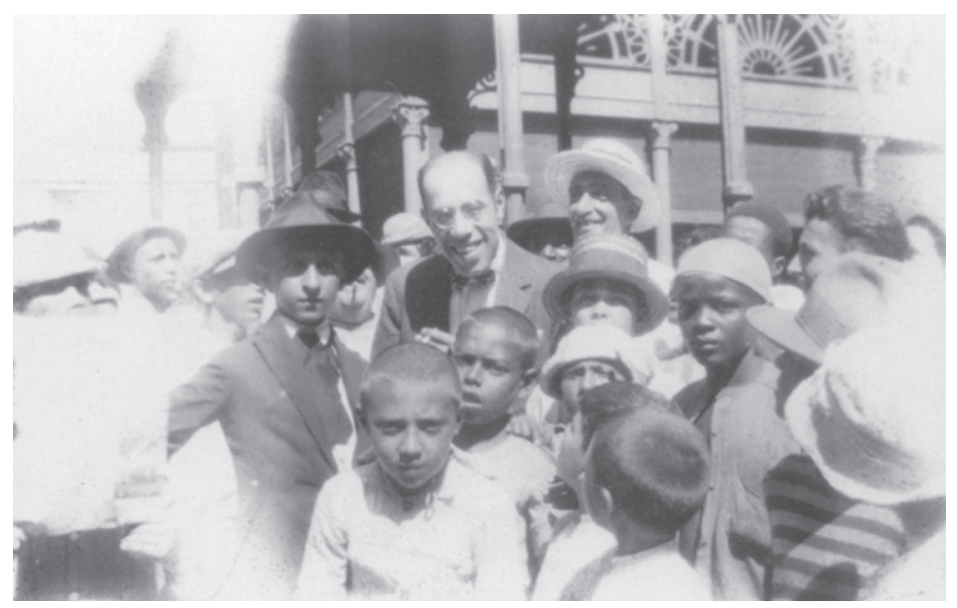

Fig. 2. "Mercado em Belém”. Código MA - 0186 IEB- USP

Por otro lado, en "Mercado en Belén”, también aparece un grupo de niños y jóvenes, aunque esta vez rodeando al propio Mário de Andrade, incorporado a la fotografía, a la vez como objeto y sujeto de la representación. El marco está visiblemente velado, resaltando el foco en el colectivo de personas. Algunos niños dirigen la mirada a la cámara, mientras otros se vuelven hacia de Andrade, localizado en el punto focal de la imagen. Hay un juego entre sombreros y cabezas descubiertas, vestidos elegantes y ropas sencillas, rostros en luz y en sombra, sujetos blancos y negros, adultos y niños, que denotan marcas raciales, sociales y culturales distintas. En este colectivo el propio sujeto se inscribe, no como un observador distante sino como un fragmento o un elemento más, incorporado al entorno. En este conjunto diverso, marcado por todo tipo de desigualdades, resalta la falta de un orden o patrón único de inteligibilidad o de visibilidad. Por otro lado, el fondo arquitectónico del mercado nada transmite que sea interpretable como parte de una fantasía turística o de un exotismo natural. Lo característico de Belén, más que el medio ambiente o la naturaleza, parece ser la propia diversidad y la desigualdad sociales, raciales y culturales, lo que es enfatizado por el modo en que el sol se imprime, de modos diferentes, en cada uno de los rostros. De hecho, lo abrasador de la luz solar tiene un efecto visible sobre las actitudes de los sujetos, que se revela en la dificultad de mirar directamente a la cámara, a través del gesto de fruncir el entrecejo, o del uso de sombreros. De este modo, la experiencia del mercado en Belén, más que como un paisaje exótico, aparece ligada a la diversidad y la desigualdad encarnada en el grupo de niños y jóvenes y al modo en que cada sujeto se enfrenta o evita la luz del sol, y en que mira o elude mirar a la cámara.

Durante los días que pasa en Belén, Mário de Andrade anota en su diario de viaje comentarios sobre el calor y menciona la experiencia, que aparece en la fotografía, de inscripción del 
viajante en el espacio del viaje: "Belém. Passeamos o dia inteiro e já me acamaradei com tudo", "Belém me entusiasma cada vez mais. O mercado hoje esteve fantástico de tão acolhedor. [...]... Tenho gozado por demais. Belém foi feita pra mim e caibo nela que nem mão dentro de luva. Em Belém o calorão dilata os esqueletos e meu corpo ficou exatamente do tamanho de minha alma". ${ }^{28}$ Se trata de un proceso por el cual el intelectual viajante se torna camarada, se "acamarada" y es acogido por el espacio del viaje, de modo tal que incorpora su propio cuerpo a dicho espacio. Como en la fotografía "Mercado en Belén", aquí el viajante es atravesado por la experiencia profunda de la alteridad que se imprime en su cuerpo a través de la luz y el calor. Como en una especie de éxtasis, la sensación física del calor, vivida en la propia carne, se traduce en una experiencia trascendente de la alteridad que transforma al sujeto, lo modifica. Y es a partir de la experiencia compartida del calor en el mercado, así como de ser alcanzado por la luz del sol y ser captado por el marco de la fotografía, que Andrade busca traducir una experiencia física de contacto en un encuentro significativo y transformador de sentidos culturales y sociales.

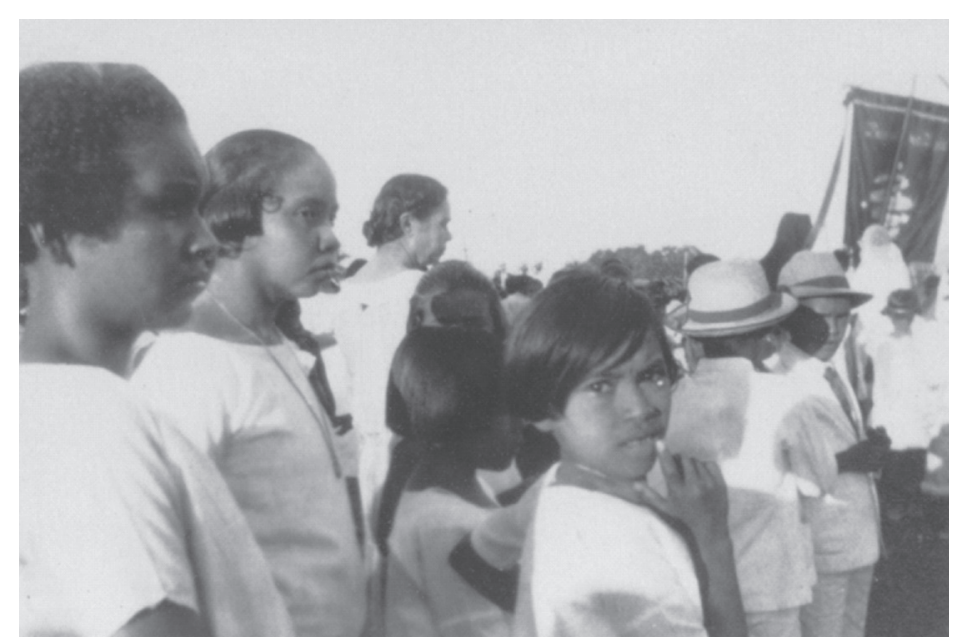

Fig. 3. "Procissão de Maria". Código MA -0209 IEB- USP

29. Ibidem, p. 87.

"Procissão de Maria" representa una procesión infantil, con la siguiente estrofa al dorso: "Santa que vai, santa que vem, tem procissão, em Santarém". Ese mismo día, Mário de Andrade escribe en su diario de viaje sobre Santarém: "Ficamos admiravelmente predispostos em favor da cidade, e as freiras fizeram uma procissãozinha infantil, com uma brisa muito agradável saindo dos estandartes". ${ }^{29}$ La fotografía capta un instante en movimiento, en que el espectador-fotógrafo queda incluido, como parte del grupo de la procesión, que se desdobla a su derecha detrás del estandarte y se pierde hacia el fondo. La imagen revela un contrapunto o un juego de opuestos entre rostros de perfil, de frente y cuerpos de espaldas, cabezas 
descubiertas y con sombrero, ropas blancas y rostros morenos, niños y adultos. Mientras las niñas de perfil permanecen indiferentes a la cámara, absortas en la observación, la niña en el centro, enfocada e iluminada, vuelve el rostro y mira directamente a la cámara, consciente de estar siendo objeto de una representación. Entre ella y la lente, entre sujeto observador y observado, se entabla una suerte de complicidad: a la vez que se descubre como objeto de interés, se vuelve ella misma sujeto de observación, lanzando una mirada inquisitiva al ojo de la cámara. Estos elementos enfatizan el carácter de la fotografía como un evento instantáneo: resaltan la inclusión del sujeto fotógrafo en el mundo representado, él mismo expuesto a la mirada de los otros, y el modo en que los sujetos representados interpelan y transforman el espacio fotográfico.

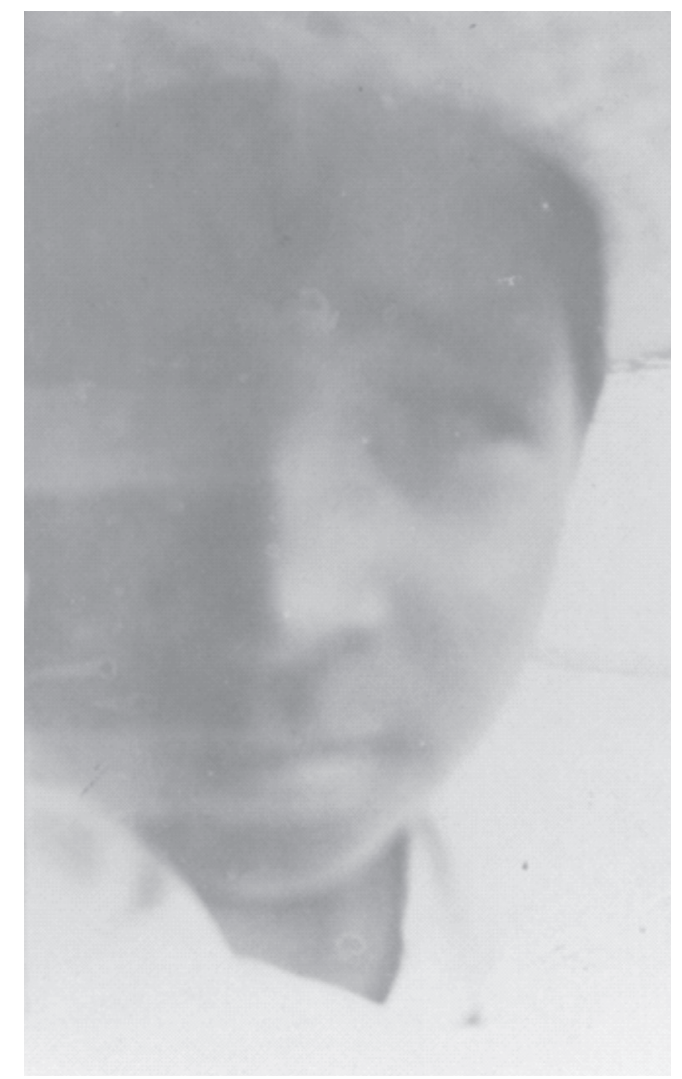

Fig. 4. "Tapuio de Parintins". Código MA - 0221 IEB - USP

Por su lado, "Tapuio de Parintins" es un retrato de un niño indígena, que transgrede las convenciones propias tanto del retrato de infancia como de la fotografía etnográfica. El retrato elimina toda distancia focal entre el fotógrafo y el modelo, propia del estudio fisionómico de carácter científico, así como la visión de frente y perfil, con fondo neutro, y la actitud corporal y psicológica que estimulan una observación objetiva, propia de la representación antropológica en uso en la época. ${ }^{30}$ En lugar de eso, el rostro del niño indígena avanza
30. Mário de Andrade contaba en su archivo fotográfico con algunas postales de indígenas brasileros que seguían estas convenciones para la representación antropológica, de lo que se deduce que conocía este tipo de normas. Al respecto, ver CANJANI, Douglas. "Mário de Andrade fotógrafo-viajante e a linguagem modernista". Revista do Instituto de Estudos Brasileiros, 2013, p. 75-76. 
31. Esther Gabara realiza un análisis interesante de la misma fotografía, en que afirma: "The photograph proclaims only that Mário and this boy were in one another's presence, without allowing the camera to capture an essential indigenous subject for a nationalist, modern art. Mário’s proximity to the boy permits him a certain intimacy and demands an ethical response to his presence, and in so doing denies him clarity of vision.”. GABARA, Esther. Errant modernism. The Ethos of Photography in Mexico and Brazil., 2008, p. 89-90. sobre el ojo de la cámara, impidiendo la intelección de los rasgos de su fisonomía. Además, la infancia, en lugar de asociada a una idea de transparencia destinada a disuadir de la espesura del instrumento fotográfico, aparece desdibujada, oscurecida, como puesta en escena precisamente de la densidad de la mirada. En lugar de un distanciamiento ante el objeto retratado, la fotografía señala el intercambio de miradas entre el sujeto retratado y el fotógrafo, que se observan mutuamente, en un juego de espejos. Como en el caso anterior, el sujeto retratado devuelve la mirada, y observa al ojo que lo mira, volviéndolo objeto de visión, exponiéndolo. Como resultado, en lugar de inteligibilidad, la fotografía transmite precisamente dificultad de visión, un conflicto o un desencuentro - una falta de foco - en el núcleo de la voluntad de representar. ${ }^{31}$

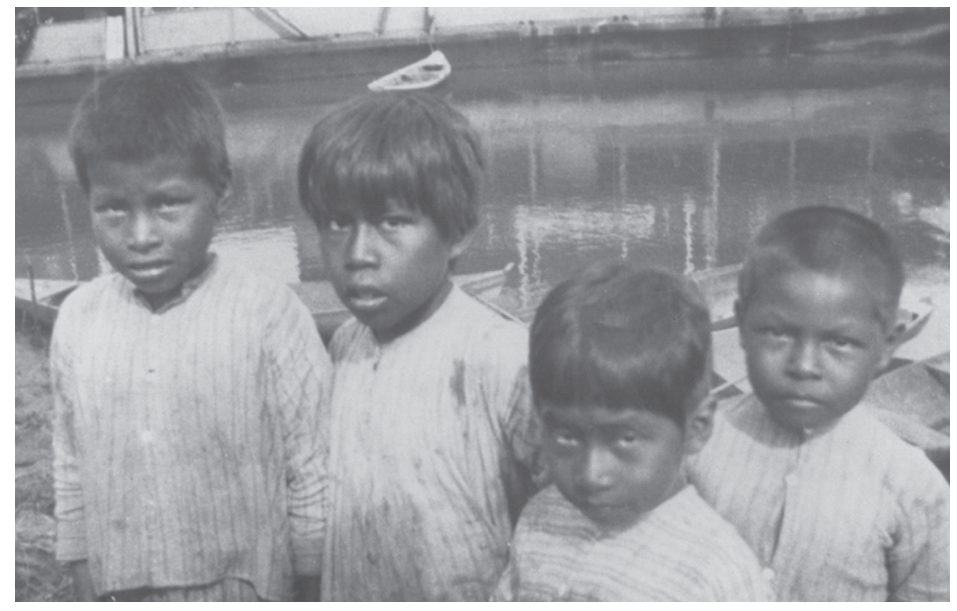

Fig. 5. “Crilas de Assacaio”. Código MA - 0290 IEB- USP

El retrato "Crilas de Assacaio", en que también aparecen niños indígenas, apunta en una dirección similar. En el dorso de la fotografía se lee: “...o homem que tirou fotografia da gente...". Los niños indígenas - "crilas" "curumins" "piazada", como los llama en otras ocasiones - retratados de 3/4, dirigen su mirada a la cámara, con una marca visible de recelo, miedo o intimidación. En lugar de una perspectiva pretendidamente neutra, la lente apunta sobre ellos desde arriba y ellos observan desde abajo, enfatizando la relación jerárquica y desigual entre ambos. De este modo, la fotografía parece preguntar: ¿Quién representa la alteridad o la extranjería? ¿Son los niños indígenas? ¿O el propio fotógrafo que avanza sobre los sujetos y sobre el espacio de visión? Como muestra tanto la fotografía como la frase citada, - "o homem que tirou fotografia da gente" el sujeto fotográfico aparece señalado, visibilizado en el acto de la representación. Al igual que los "Crilas de Assacaio", el fotógrafo es designado como un "hombre", es decir, despojado de nombre y de individuación. La frase denota el mismo 
tono acusatorio que las miradas. En lugar de como producto de la intención de documentar fisonomías raciales, trajes típicos o sujetos exóticos, aquí la fotografía pone en escena el encuentro ominoso y cargado de violencia entre el fotógrafo y los sujetos fotografiados, unos en presencia del otro. Las ropas no son típicas, si no que denotan pobreza y suciedad; los rostros, en lugar de exotismo o tipicidad, transmiten extrañeza e incomodidad, un conflicto indisimulado. Como la frase, las miradas recelosas, desde un ángulo inferior, exponen la presencia del "extraño", el "hombre que saca fotografías", revelando así el carácter conflictivo del encuentro, así como la perspectiva doble de la representación, por la cual el fotógrafo se vuelve objeto representado y los indígenas retratados se vuelven sujetos de la enunciación.

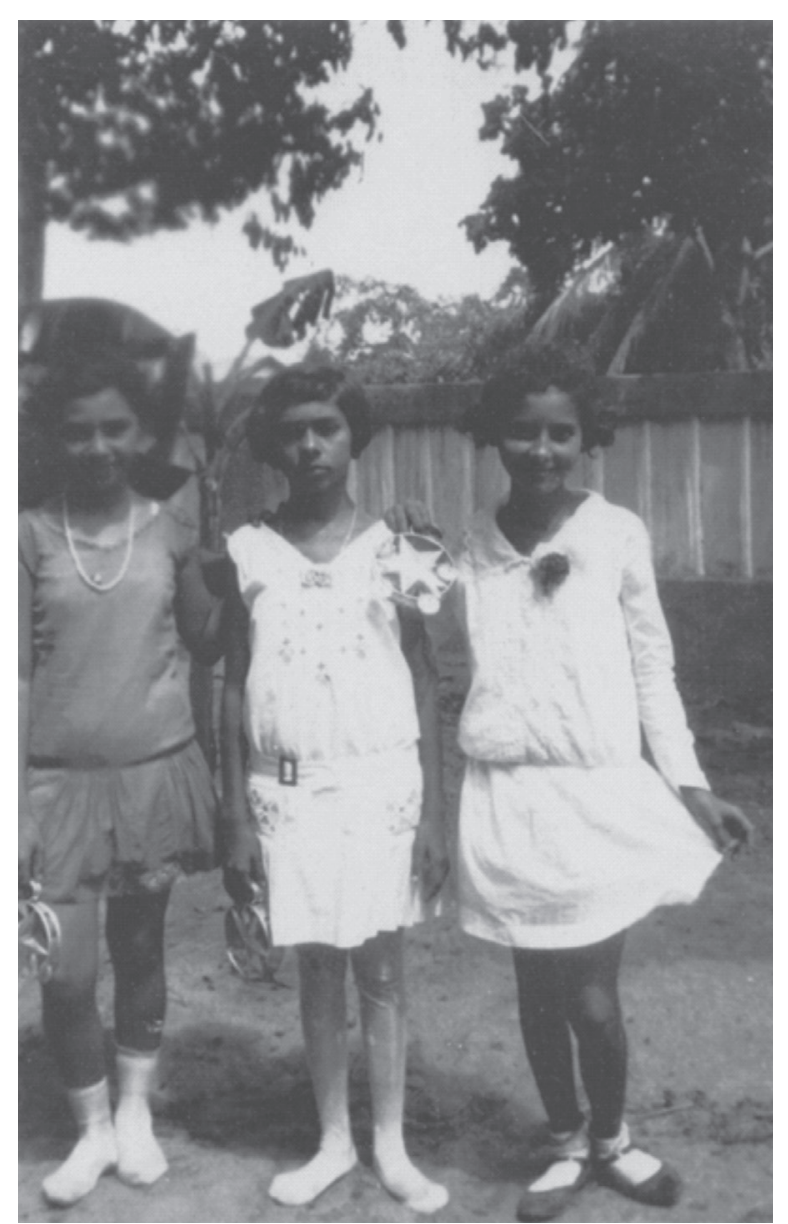

Fig. 6. "Pastoril (ensaio)". Código MA - 0887 IEB- USP

Por otro lado, en "Pastoril (ensayo)" - fotografía proveniente de su viaje al Nordeste -, aparecen tres niñas visiblemente listas para bailar un "pastoril", danza folclórica nordestina, con panderetas en las manos. Dice Mário de Andrade en su crónica del Diário Nacional, como parte del relato de su viaje al Nordeste: 
32. ANDRADE, Mário de.

O Turista Aprendiz, 2015, p. 288.
Guardado da rua, no "sítio" (chacra) do coronel Cascudo, as meninas bailam no Pastoril. São umas deliciosas de cunhatãs, desacompanhadas a piano e violino, com tanta graça, tanta desenvoltura no gesto que o futuro da pátria aqui está. A maior não terá doze anos porém dançam com um ar de "frevo", num mexido sensual tão inconsciente como a fatalidade. Umas defendem o cordão encarnado. Outras o azul. No meio a Diana, caçadora sem nenhuma Grécia, celebra com gostosura o nascimento de Jesus, menina linda, graça esplêndida, estrelinha nos cabelos, pandeiro prateado na mão. Não tem dúvida que o espetáculo é um bocado "bibliothèque rose" porém agrada os meus passeios". ${ }^{32}$

El relato de viaje señala la sensualidad inconsciente de las niñas, que se revela en el baile del pastoril. Como parte del rito y la danza folclórica, con sus panderos y sus ornamentos, las niñas se tornan portadoras de una idea de futuro patrio bastante particular: llena de sensualidad, de pulsiones inconscientes, excesiva en su sentimentalismo, encarnada y material. El retrato fotográfico apunta en una dirección similar. Se trata de tres niñas de cuerpo entero, posando para la foto: mientras que las dos niñas a los lados miran directamente a la cámara, sonriendo, con una postura graciosa, sensual, la que está en el centro permanece seria, desgarbada y neutra, con la mirada perdida. Como escenificación de una danza regional, el retrato de estas niñas no apunta a una idea de inocencia o pureza sino a una sensualidad pícara, a una sentimentalidad casi excesiva y a un aire misterioso. Estas niñas señalan diferentes estrategias de seducción: apuntan al carácter profundamente corporal, terreno, del mito y el rito y encarnan el sentido material y tangible del futuro cívico.

Algo similar sucede en "Futuro corpo sublime", retrato de una niña en la playa de Redinha, en Natal, también proveniente del viaje al Nordeste. La joven aparece de cuerpo entero, en una pose que transmite gracia y sensualidad: se toma el vestido con las manos y dirige una mirada pícara a la cámara. Descalza en la playa, sonriente y con los cabellos desordenados, esta niña encarna un tipo de "sublimidad" carnal y terrena, lejos de la inocencia del retrato infantil convencional. La imagen de esta niña, desprovista de cualquier marca de nostalgia, escenifica una pulsión sexual vuelta hacia al futuro. Sin marcas de clase, ornamentos o accesorios, esta niña despliega una potencia de seducción, como parte de una retórica visual despojada y espontánea. La niña entabla con el ojo de la cámara un juego de atracción, magnetismo y misterio que ya aparecía en la fotografía anterior. De este modo, el retrato invita al observador a participar de la experiencia, plena de sensualidad, de la juventud en la playa. 


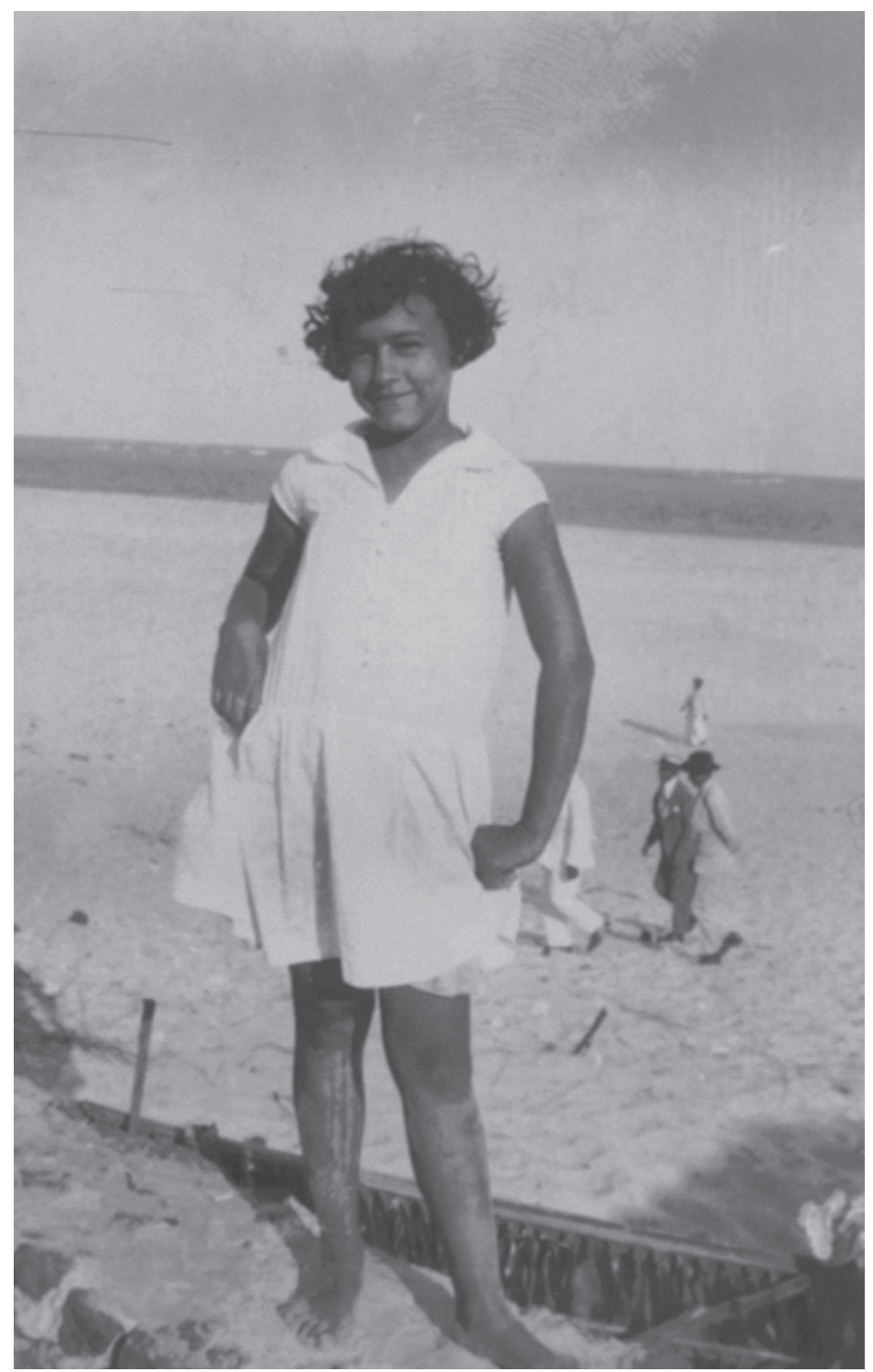

Fig. 7. "Futuro Corpo Sublime". Código MA - 0906 IEB - USP

Como este trabajo intentó demostrar, el retrato de infancia funciona, en la obra literaria y fotográfica de Mário de Andrade, como una suerte de inconsciente fotográfico. La infancia pone en escena la densidad de la propia mirada, ya sea como revelación de la no coincidencia del sujeto consigo mismo, la cesura entre el yo y su representación, o como indicio del encuentro conflictivo y cargado de tensiones - culturales, raciales, sociales y sexuales entre el fotógrafo y los sujetos retratados, por el cual el primero se expone, se visibiliza en el acto de la representación y estos últimos interpelan y transforman el espacio fotográfico. 


\section{Referencias}

ANDRADE, Mário de. Contos novos. Rio de Janeiro: Nova Fronteira, 2011.

. O Turista Aprendiz: Brasília: Iphan, 2015.

ARIÈS, Philippe. Centuries of Childhood: a Social History of Family Life. New York: Knopf, 1962.

AZOULAY, Ariella. The Civil Contract of Photography.

Cambridge: MIT Press, 2008.

BARTHES, Roland. Roland Barthes por Roland Barthes.

Barcelona: Paidós, 2004.

BENJAMIN, Walter. Berlin Childhood around 1900. London: Belknap, 2006.

. "Little History of Photography". In: Walter

Benjamin: Selected Writings. Vol. 2. Cambridge: Harvard Univ. Press, 1999.

BERGER, John. "The Changing View of Man in the Portrait". In:__. Selected Essays. New York: Random House, 2003.

BOTELHO, André. "A viagem de Mário de Andrade à Amazônia: entre raízes e rotas." Revista do Instituto de Estudos Brasileiros. n. 57, 2013.

BOTELHO, André; LIMA, Nísia Trindade. "Malária como doença e perspectiva cultural nas viagens de Carlos Chagas e Mário de Andrade à Amazônia." História, Ciências, Saúde Manguinhos. V. 20, n. 3, p. 745-763, 2013.

BRIZUELA, Natalia. Depois da fotografia: uma literatura fora de si. Rio de Janeiro: Ed. Rocco, 2014.

CAMPOS, Luna Ribeiro. Sensibilidade etnográfica, narrativa e interpretação do Brasil: a viagem de Mário de Andrade ao Nordeste (1928-1929). Dissertação de mestrado. PPGSA. UFRJ. 2014.

CANJANI, Douglas. "Mário de Andrade fotógrafo-viajante e a linguagem modernista". Revista do Instituto de Estudos Brasileiros, n. 57 , p. 51-82, 2013.

FABRIS, Annateresa. Identidades Virtuais: uma leitura do retrato fotográfico. Belo Horizonte: Editora UFMG, 2004.

FOSTER, Hal. "The Artist as Ethnographer?” In: . The Return of the Real. Cambridge: MIT Press, 1996.

GABARA, Esther. Errant modernism. The Ethos of Photography in Mexico and Brazil. Durham: Duke Univ. Press, 2008. 
Galvão Coutinho, Rejane. A coleção de Desenhos Infantis do Acervo Mário de Andrade. Tese. Universidade de São Paulo, Escola de Comunicações e Arte, 2002.

HIGONNET, Anne. Pictures of Innocence: The History and Crisis of Ideal Childhood. New York: Thames and Hudson, 1998.

JOSIOWICZ, Alejandra. La cruzada de los niños. Infancia y cultura en América Latina (1880-1980). Tese. Princeton University, 2013. "Por uma política da estética em Mário de Andrade: Expressionismo e Infância." Sociologia \& Antropologia. v. 05.03, p. 799-823, 2013.

LOPEZ, Telê Ancona. "Um contista bem contado" In: . Mariodeandradeando. São Paulo: Editora Hucitec, 1996. "O turista aprendiz na Amazônia: a invenção no texto e na imagem”. Anais do Museu Paulista. v. 13, n. 2, 2005.

LOPEZ, Telê Ancona; RANIERO FERNANDEZ, Leandro, "Os diários do fotógrafo". In: ANDRADE, Mário de.

O Turista Aprendiz: Brasília: Iphan, 2015.

MOTTA, Flávio (Org.). Depoimentos 2/ Mário de Andrade. São Paulo: Grêmio da Faculdade de Arquitetura e Humanismo da USP, 1966 
